\title{
A test of niche centrality as a determinant of population trends and conservation status in threatened and endangered North American birds
}

\author{
Joseph D. Manthey ${ }^{1, *}$, Lindsay P. Campbell ${ }^{1}$, Erin E. Saupe ${ }^{1,2}$, Jorge Soberón ${ }^{1}$, \\ Christopher M. Hensz ${ }^{1}$, Corinne E. Myers ${ }^{2}$, Hannah L. Owens ${ }^{1}$, Kate Ingenloff ${ }^{1}$, \\ A. Townsend Peterson ${ }^{1}$, Narayani Barve ${ }^{1}$, Andrés Lira-Noriega ${ }^{1}$, Vijay Barve ${ }^{1}$ \\ ${ }^{1}$ Biodiversity Institute, University of Kansas, Dyche Hall, 1345 Jayhawk Blvd., Lawrence, KS 66045-7561, USA \\ ${ }^{2}$ Department of Geology and Geophysics, Yale University, 210 Whitney Ave., New Haven, CT 06511, USA \\ ${ }^{3}$ Dept. of Organismic and Evolutionary Biology, Harvard University, 26 Oxford St., Cambridge, MA 02139, USA
}

\begin{abstract}
Abundance and other aspects of population ecology have long been known to contribute to shaping the geography of species' distributions. In particular, abundance patterns have recently been shown to negatively correlate with environmental distance from conditions in the center of a species' abiotic niche, rather than vary with distance from the geographic center of a species' distribution. We tested for such associations across 8 species of endangered or threatened bird species in North America using population trend data derived from $>4$ decades of North American Breeding Bird Surveys. Although we found no consistent overall pattern, we did observe negative population trends at conditions that were the most extreme within species' niches. This suggests that niche peripherality is a relevant factor to consider in conservation planning. Specifically, environmentally peripheral sites may be poor places in which to protect populations of endangered and threatened species, irrespective of how centrally they may occur within species' geographic distributions.
\end{abstract}

KEY WORDS: Ecological niche - Geographic range - Environmental suitability · Threatened species · Endangered species · Population trends

\section{INTRODUCTION}

The abundant center hypothesis (ACH), also known as Brown's Principle, states that species will be most abundant close to the centers of their geographic ranges. As distance increases from this geographic center, abundance is expected to decrease until distributional limits are reached (Brown 1984, Hengeveld 1992). This idea has been explored and tested extensively, and has often been utilized as a null hypothesis for explaining spatial distributions of abundance (Lawton 1993, Lesica \& Allendorf 1995, Curnutt et al. 1996). Although intuitive to some degree, ACH predictions see only variable success (Sagarin \& Gaines 2002): many exceptions exist, re-

${ }^{*}$ Corresponding author: jdmanthey@gmail.com flecting the fact that suitability of a place for a species is a function of environmental conditions, which do not vary linearly from the geographic center of a species' distribution. Consequently, often a simple correspondence between the center of a species' geographic range and the highest areas of environmental suitability does not exist (Myers \& Saupe 2013).

While the traditional, geographically based $\mathrm{ACH}$ relationships (henceforth termed $\mathrm{ACH}_{\mathrm{G}}$ ) are often not manifested, recent work suggests that abundance patterns respond predictably to centrality versus peripherality in the multidimensional environmental space that defines a species' scenopoetic niche (Martínez-Meyer et al. 2013, Lira-Noriega \& Manthey 2014); that is, the set of abiotic conditions

() The authors 2015. Open Access under Creative Commons by Attribution Licence. Use, distribution and reproduction are unrestricted. Authors and original publication must be credited. 
that a species can tolerate (Peterson et al. 2011). Populations tend to be more abundant near the center of a species' environmental range and decline with environmental distance from this centroid, irrespective of where these environments occur geographically. These niche-based abundance relationships, first noted by Brown (1984), could be termed as an environmentally based $\mathrm{ACH}$ (hence $\mathrm{ACH}_{\mathrm{E}}$ ). The geographic distribution of environmentally suitable areas may contrast with the spatial geometry of a species' range, such that geographically central regions may be environmentally peripheral, and geographically peripheral areas may be environmentally central (Fig. 1). A recent study documented that population densities relate consistently to $\mathrm{ACH}_{\mathrm{E}}$, but poorly or inconsistently to $\mathrm{ACH}_{\mathrm{G}}$, suggesting that distances to environmental (scenopoetic) niche centroids may be more relevant to population biology of species than distances from geographic range centroids (Martínez-Meyer et al. 2013). Similar contrasts between $\mathrm{ACH}_{\mathrm{E}}$ and $\mathrm{ACH}_{\mathrm{G}}$ have been documented as regards standing genetic diversity: the largest genetic variation is observed at locations within environments that map in the center of a species' multidimensional scenopoetic niche, and genetic variability declines with increasing environmental distance from this center; no relationship was observed between centrality and peripherality in geographic space (Lira-Noriega \& Manthey 2014).

Here, we test for an additional $\mathrm{ACH}_{\mathrm{E}}$ and $\mathrm{ACH}_{\mathrm{G}}$ effect: whether population growth rates and conservation threat status vary with distance from the environmental and/or geographic center of species' distributions. A negative relationship between population size and population growth rate is well known when no Allee effect is present (Sibly et al. 2005), with the intercept given by the intrinsic growth rate of the population. We hypothesize a negative relationship between environmental distance to the scenopoetic niche centroid and population trends. Such a relationship has important implications for biological conservation, since the majority of protected areas for threatened species are currently based on the geographical $\mathrm{ACH}_{\mathrm{G}}$. If population trends are correlated with distance from the niche centroid (i.e. supporting the $\mathrm{ACH}_{\mathrm{E}}$ ), then strategies for designating protected areas will need to consider species' niches in order to maximize conservation success. Specifically, here we tested whether environmental and/or geographic centrality can explain geographic variation in population trends among 8 bird species, each with at least some populations listed under the US Endangered Species Act. We
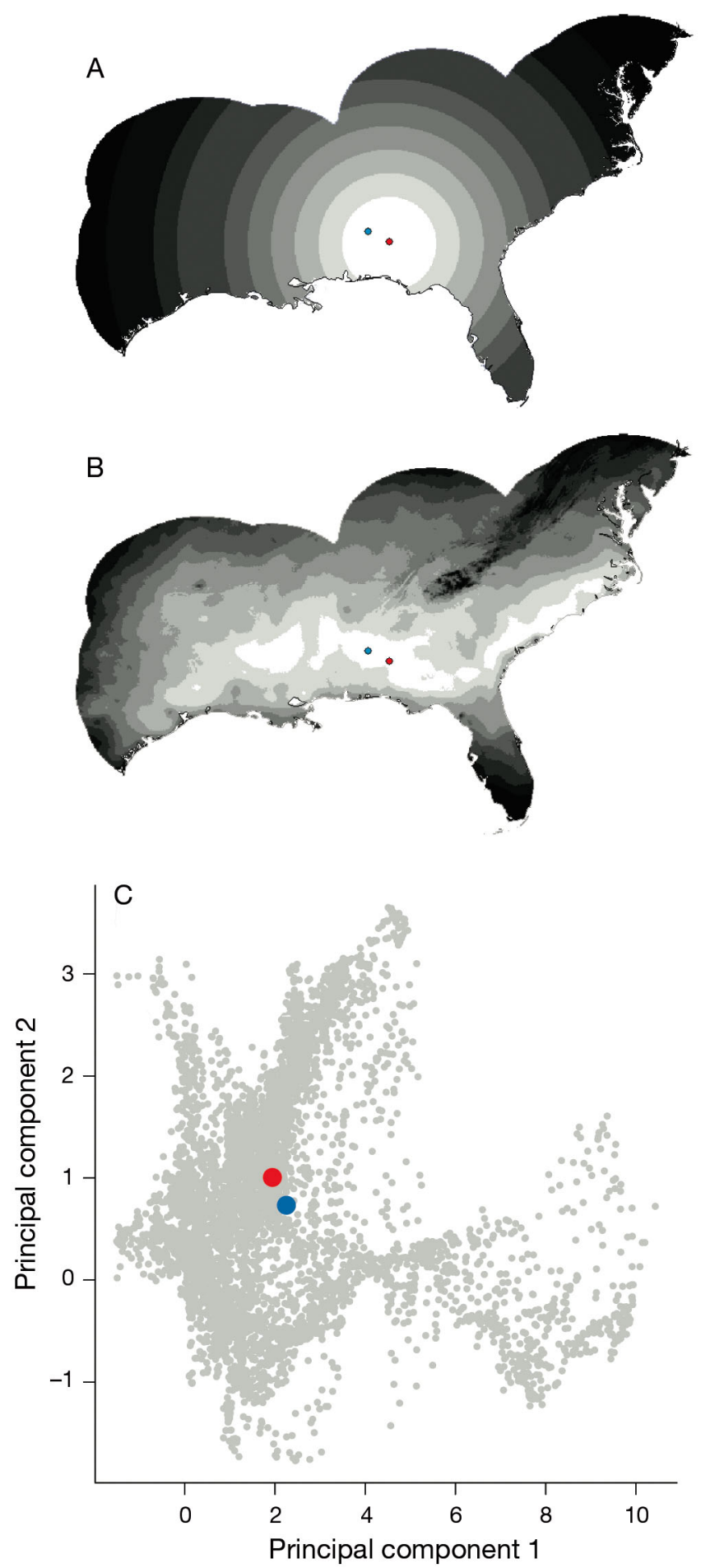

Fig. 1. (A) Distributions of distances to the geographic range center (red dot) and (B) distance to the ecological niche centroid (blue dot) across the geographic range of the redcockaded woodpecker Picoides borealis. Range center and niche centroid are indicated in all panels. Darker gray shading indicates greater distances from the centroid. (C) Plot of conditions available across the region in a 2-dimensional environmental niche space, showing geographic and ecological niche centroids 
used population-trend surfaces developed by the North American Breeding Bird Survey (BBS) for the United States and Canada (Sauer et al. 2012) as the response variable in our tests.

\section{MATERIALS AND METHODS}

\section{Selection of study species}

Eight bird species (Table 1) were selected for analysis based on the following criteria: (1) listed as threatened or endangered under the US Endangered Species Act; (2) no micro-endemism (e.g. we excluded Aphelocoma insularis, endemic to Santa Cruz Island in the California Channel Islands); (3) distribution not limited strictly by geographic barriers (see discussions of accessible areas in Barve et al. 2011, Saupe et al. 2012), which would make for ecological niche models that do not capture physiological response patterns effectively (Owens et al. 2013); and (4) trend maps summarizing change in abundance available from the North American BBS across most of the species' geographic distribution.

\section{Input data preparation}

We obtained geographic coordinates of unique occurrence points for each species from VertNet

Table 1. Results of linear regressions relating population trends to environmental distances from niche centroids for 8 species of threatened and endangered bird species. Asterisks indicate significant $(p<0.05)$ sign tests in the outer quartile of the distance distribution

\begin{tabular}{|lrrrr|}
\hline Species & Intercept & Slope & $\mathrm{R}^{2}$ & $\mathrm{p}$ \\
\hline Overall & & & & \\
Ammodramus savannarum & -6.267 & 1.139 & 0.017 & $<0.001$ \\
Empidonax traillii & 2.055 & -0.378 & 0.007 & $<0.001$ \\
Grus canadensis & 11.329 & -1.240 & 0.008 & $<0.001$ \\
Lanius ludovicianus & -1.631 & -0.352 & 0.003 & $<0.001$ \\
Melozone crissalis & 0.190 & -0.191 & 0.008 & 0.019 \\
Picoides borealis & 1.390 & -1.274 & 0.290 & $<0.001$ \\
Tympanuchus cupido & 13.053 & -4.778 & 0.125 & $<0.001$ \\
Vireo bellii & -2.752 & 1.214 & 0.014 & $<0.001$ \\
Outer quartile only & & & & \\
Ammodramus savannarum & 15.261 & -2.776 & 0.021 & 0.539 \\
Empidonax traillii & -10.134 & 0.607 & 0.114 & 0.091 \\
Grus canadensis & 4.569 & -0.141 & 1.000 & 0.003 \\
Lanius ludovicianus* & -10.651 & 1.059 & 0.002 & 0.571 \\
Melozone crissalis* & 9.963 & -2.126 & 0.162 & 0.098 \\
Picoides borealis & 18.516 & -3.866 & 0.282 & 0.001 \\
Tympanuchus cupido* & 32.002 & -11.047 & 0.047 & 0.007 \\
Vireo bellii & 19.537 & -5.307 & 0.221 & 0.002 \\
\hline
\end{tabular}

(www.vertnet.org) and eBird (Sullivan et al. 2014). Data from Backyard Birdwatch and Project Feederwatch were not included in analyses due to concerns with accuracy of species-level identifications. Data were reduced further to include only occurrences during breeding-season months. When georeferencing precision was known, only points with locational uncertainty finer than the geographic resolution of our climate data were included (4 to $5 \mathrm{~km}$ ); we reduced occurrences such that only single records remained per pixel (at a 2.5' grid resolution) using the 'distancefilter' function in the ENMGadgets package in R (Barve \& Barve 2013). Sample sizes after these filtering steps are provided for each species in Table S1 in the Supplement at www.int-res.com/articles/suppl/ n026p201_supp.pdf.

To document population trends for each species, we downloaded maps from BBS illustrating bird population trends during the period 1966 to 2011. BBS data consist of roadside visual and audio identification records of bird species collected every $\sim 1 \mathrm{~km}$ along designated $40 \mathrm{~km}$ routes across the USA and Canada during peak breeding-season months (www. pwrc.usgs.gov/bbs). From these surveys, population trend maps have been created based on routeregression weights and interpolation with an inverse distance function, as described in detail by Link (1994).

Considerable evidence suggests that abiotic factors tend to limit a species' distribution at regional scales, whereas biological factors, such as vegetative habitat, tend to be significant at more local scales (Soberón 2007). Consequently, to characterize climatic variation for niche model calibration, we used 15 'bioclimatic' variables at 2.5' resolution (Hijmans et al. 2005): annual mean temperature, mean diurnal temperature range, isothermality, temperature seasonality, maximum temperature of warmest month, minimum temperature of coldest month, annual temperature range, mean temperatures of warmest and coldest quarters, annual precipitation, precipitation of wettest and driest months, precipitation seasonality, and precipitation of wettest and driest quarters. These data are derived from monthly temperature and precipitation summaries of weather station data from approximately 1950 to 2000 . 
Models were calibrated within a region hypothesized to be accessible to a species (M) and sampled sufficiently (S). Following the suggestions of Barve et al. (2011; Appendix A), M hypotheses were based on breeding distribution occurrences, landscape continuity that would affect access to surrounding areas, published literature on avian distributions, and consultation with ornithologists at the University of Kansas. S areas were identified via visual comparisons of known distributional areas with available occurrence data for each species. Models were calibrated across the unique $\mathbf{M} \cap \mathbf{S}$ for each species spanning all or most of each species' range; however, $\mathrm{ACH}$ analyses (see 'Model analysis') were restricted to the North American part of the species' range, where BBS trend data were available.

Climate data layers were also masked to the extent of $\mathbf{M} \cap \mathbf{S}$ for each species, again following Barve et al. (2011), using the 'CropRaster' function in the ENMGadgets R package (Barve \& Barve 2013). We centered and standardized data in each layer, performing a principal components analysis (PCA) on the correlation matrix using the 'PCARaster' function in the ENMGadgets package (Barve \& Barve 2013) in R (R Core Team 2013). We retained the first 5 components, which explained cumulatively $\geq 95 \%$ of total variance in the dataset, for model calibration. In light of recent studies documenting the negative effects of peripherality of occurrence data with respect to environmental space across $\mathbf{M} \cap \mathbf{S}$ (Owens et al. 2013), we assessed whether occurrence data plotted in the center or periphery of histograms that depicted each environmental variable used for ENM analysis. Histograms were produced using the 'NicheViews' function in ENMGadgets in R (Barve \& Barve 2013). When occurrence peripherality was observed with respect to a single environmental variable only, that variable was removed to avoid extrapolation in the modeling process (e.g. principal component 3 [PC3] for greater prairie chicken; see summary in Table S1 in the Supplement).

\section{Ecological niche modeling}

Ecological niche models were generated using the maximum entropy algorithm Maxent (Phillips et al. 2006) on default settings. Maxent relates environmental values associated with known occurrences of species to those of a sample of background points to estimate environmental requirements and potential distributional areas (Elith et al. 2011, Peterson et al. 2011). Model outputs were thresholded via a least training presence approach (Pearson et al. 2007) and modified to allow 1 to $5 \%$ omission based on estimated error rates (Table S1 in the Supplement; Peterson et al. 2008, 2011). Model performance was assessed using a cumulative binomial test, for which we used 50 occurrence points that had been set aside from the available pool before model calibration; the null probability of successful prediction of occurrence points was taken as the proportion of area predicted as suitable across $\mathbf{M} \cap \mathbf{S}$ (Peterson et al. 2011).

\section{Model analysis}

The $\mathrm{ACH}_{\mathrm{G}}$ and $\mathrm{ACH}_{\mathrm{E}}$ were calculated as follows: ecological niche centroids were derived as the mean of the PC layers used in model calibration for the set of pixels identified as suitable by the thresholded Maxent model. We measured Euclidean distance in environmental units from each suitable pixel to the environmental centroid using the 'fields' package in R (Furrer et al. 2012). The geographic centroid was identified as the spatial centroid of the geographic region identified as suitable; we measured geographic distance from each suitable pixel to the geographic centroid of suitable pixels using the 'geosphere' package in R (Hijmans et al. 2012). Finally, we used the BBS trend polygon datasets to group pixels identified as suitable by the Maxent algorithm. We calculated average environmental and geographic centroid distances across all pixels falling within each of the coarser-resolution BBS polygons.

We used linear and quadratic regression models to explore relationships between trends in species' abundance and environmental and geographic centroid distances. To test whether population trends were only affected by distances beyond a certain threshold, we divided distance data into quartiles; linear regressions were repeated on the outermost quartile. We similarly used sign tests to assess whether data in the outer quartile fell non-randomly below zero in population trend, i.e. whether populations in the outer quartile tended towards negative trends.

\section{RESULTS}

Ecological niche models estimated potential distributional areas for each species that corresponded roughly with known range limits and with the occurrence data on which they were based (Fig. 2; Figs. S1 to S7 in the Supplement at www.int-res.com/articles/ 

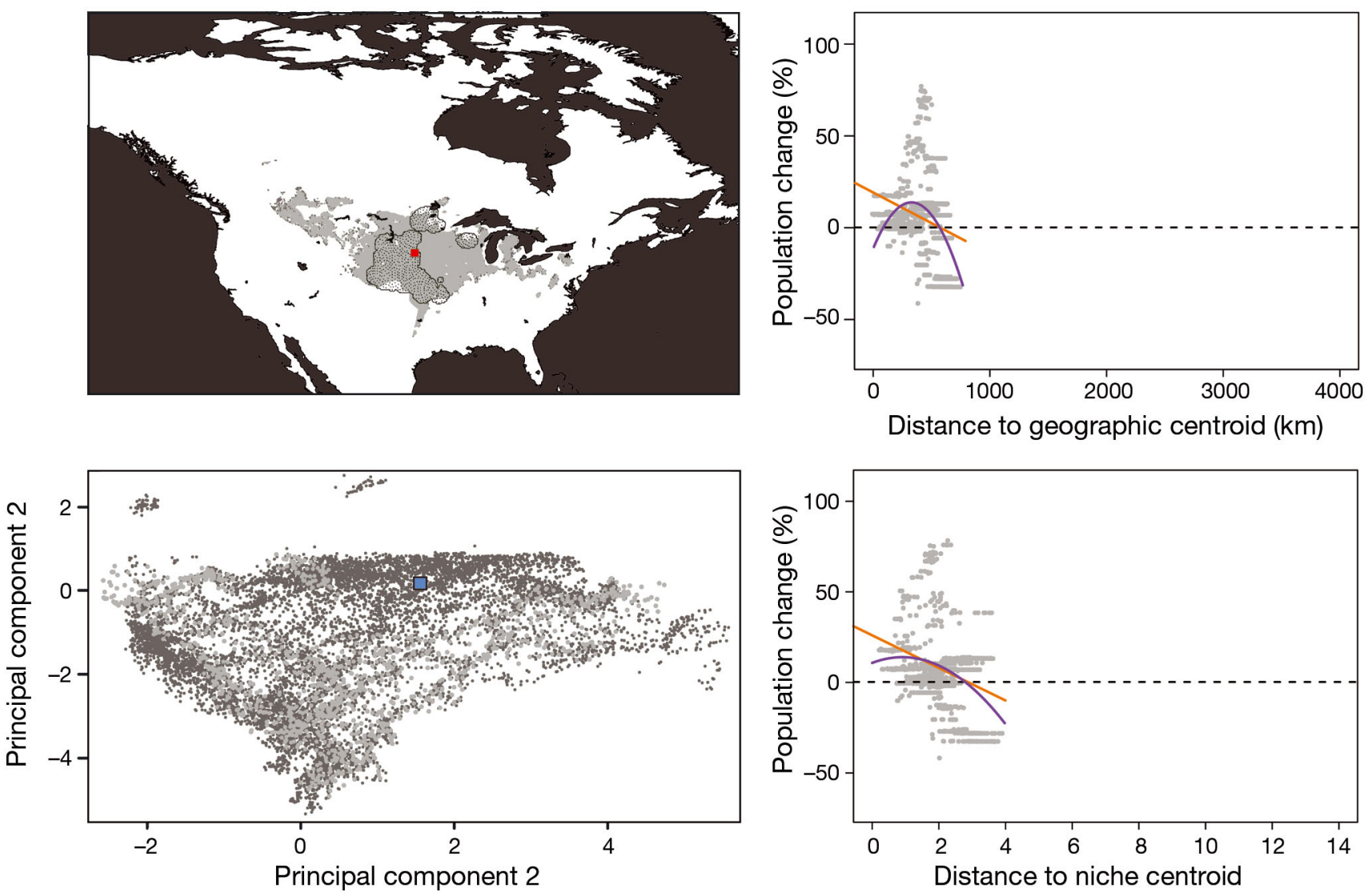

Fig. 2. Example of geographic and environmental distance comparisons explored in this study: greater prairie chicken Tympanuchus cupido. Upper left: Distribution of modeled suitable areas (light gray), extent of Breeding Bird Survey area (stippled), and geographic centroid of the distribution (red). Lower left: Available combinations of the environmental space (light gray), suitable combinations of environmental variables (dark gray) and environmental centroid (blue square). Upper right: Population trends versus distance to geographic centroid $(\mathrm{km})$ with linear (orange) and quadratic (purple) models. Lower right: Population trends versus distance in environmental space to the environmental centroid with linear (orange) and quadratic (purple) models. Comparisons for other species, see Figs. S1 to S7 in the Supplement

suppl/n026p201_supp.pdf). Model predictions for all 8 species showed predictive ability better than null expectations based on the binomial tests $(\mathrm{p}<0.05)$ (Table S1 in the Supplement). Hence, we were justified in exploring the implications of these models as regards population trends.

Regressions of population trends on environmental niche distances all showed best fit with linear functions (Fig. 2, Figs. S1 to S7). Although all regression models were statistically significant, $\mathrm{R}^{2}$ values were low, ranging only from 0.003 to 0.290 (Table 1). Six species showed negative slopes (Empidonax traillii, Grus canadensis, Lanius ludovicianus, Melozone crissalis, Picoides borealis (Figs. S2 to S6, respectively), and Tympanuchus cupido, Fig. 2 main text), but the remaining two showed positive relationships (Figs. S1 \& S7); this six-to-two imbalance was not significant (cumulative binomial test; $\mathrm{p}=0.1445$ ). Geo- graphic centroid distance relationships were also mixed, showing an equal negative to positive slope ratio, although all slopes were essentially indistinguishable from zero (Table 2).

We explored population trend-distance relationships in the outer quartiles of environmental and geographic distances for each species. This test investigated whether populations may respond to declining environmental suitability only outside a specified distance. We hypothesized that if a threshold effect existed, then a negative relationship between population trend and distance would become apparent in regions farthest from the center of suitability for a species. The only significant relationships (T. cupido, G. canadensis, P. borealis, Vireo bellii) for outer quartiles of environmental distances were negative (Table 1) - this degree of imbalance (i.e. tendency toward negative relationships) was somewhat 
Table 2. Results of linear regressions relating population trends to geographic distances to range centroids for 8 species of threatened and endangered bird species. Note that slopes have been multipled by 1000 for ease of visualization, indicating all are close to zero. Asterisks indicate significant $(p<0.05)$ sign tests in the outer quartile of the distance distribution

\begin{tabular}{|lrrrc|}
\hline Species & Intercept & Slope & $\mathrm{R}^{2}$ & $\mathrm{p}$ \\
\hline Overall & & & & \\
Ammodramus savannarum & -4.722 & 0.001 & 0.011 & $<0.001$ \\
Empidonax traillii & 1.995 & -0.001 & 0.008 & $<0.001$ \\
Grus canadensis & 5.008 & 0.003 & 0.009 & $<0.001$ \\
Lanius ludovicianus & -4.055 & 0.001 & 0.011 & $<0.001$ \\
Melozone crissalis & 0.819 & -0.002 & 0.043 & $<0.001$ \\
Picoides borealis & 1.338 & -0.007 & 0.222 & $<0.001$ \\
Tympanuchus cupido & 9.786 & -0.017 & 0.075 & $<0.001$ \\
Vireo bellii $^{\text {Outer quartile only }}$ & -1.828 & 0.003 & 0.015 & $<0.001$ \\
Ammodramus savannarum & ${ }^{*}$ \\
Empidonax traillii & -33.109 & 0.016 & 0.122 & $<0.001$ \\
Grus canadensis & -13.163 & 0.007 & 0.058 & $<0.001$ \\
Lanius ludovicianus* $^{*}$ & 44.109 & -0.013 & 0.469 & $<0.001$ \\
Melozone crissalis* & -30.761 & 0.014 & 0.029 & $<0.001$ \\
Picoides borealis $^{*}$ & -1.427 & 0.001 & 0.002 & 0.626 \\
Tympanuchus cupido* & -3.538 & 0.002 & 0.002 & 0.566 \\
Vireo bellii $^{*}$ & 57.110 & -0.100 & 0.219 & $<0.001$ \\
& 2.523 & -0.002 & 0.001 & 0.469 \\
\hline
\end{tabular}

and diverse statistical analyses. Finding both negative and positive overall linear relationships, we envisioned that population trends might only respond to more extreme environmental distances, creating flat or inconsistent relationships across much of the range of distances. In other words, population trends might show a negative response to distance from the environmental centroid only beyond some distance threshold (prior to which populations may be buffered by other properties, e.g. biotic interactions or other intrinsic population characteristics). These latter tests showed clearer relationships: 4 species showed significant population trends in the fourth quartile, all negative, providing support for a revised hypothesis of declining populations in environmentally peripheral populations. Geography-based distance tests showed a less consistent pattern.

unexpected (cumulative binomial test, $\mathrm{p}=0.1445$ ). In contrast, outer quartiles of geographic distances showed 2 significantly negative and 3 significantly positive relationships (sign test, $\mathrm{p}>0.5$; Table 2). Testing whether population trends tended to be negative in the outer quartile, 4 species (L. ludovicianus, M. crissalis, P. borealis, T. cupido) presented significant results using environmental distances, and 5 species (Ammodramus savannarum, L. ludovicianus, M. crissalis, P. borealis, T. cupido) presented significant results using geographic distances (Tables 1 \& 2).

\section{DISCUSSION}

Our original hypothesis was that population trends might vary negatively with distance to optimal environmental conditions, posited as the centroid of the species' potential distribution in environmental space. This idea was posed in contrast to more traditional views, which have referred to centroids of geographic distributions. Two recent papers have shifted to such a niche-based view, finding that distance from the niche centroid explains trends in population abundance (Martínez-Meyer et al. 2013) and standing genetic variation (Lira-Noriega \& Manthey 2014). Our hypothesis, however, saw only variable support in our overall analyses of 8 bird species in North America, in spite of many quality control measures
One possible interpretation of the lack of comprehensive support for our initial (simplest) hypothesis - and clearly the most responsible — is the straightforward one: that no relationship exists. Thus, whereas abundances appear to respond closely to ecological niche centroid distances (Yañez-Arenas et al. 2012, Martínez-Meyer et al. 2013), changes in population growth rate or population robustness in the face of habitat perturbation and fragmentation do not necessarily respond similarly. Rather, population trends may respond more locally to aspects of land use and conservation of native habitats, particularly for species showing some sort of endangerment: in other words, local landscape processes such as urbanization, deforestation, or fragmentation of native vegetation may drive local increases and decreases in populations, rather than the degree of climatic suitability.

Alternatively, however, a relationship between niche centrality and population trend may exist in some species, but not universally in all species. In other words, this pattern may be species specific and is not found in species with particular ecologies, lifehistory traits, or challenges to their persistence (e.g. hunting, disease, habitat destruction, climate change). The question remains open, given that the number of species analyzed herein is not sufficient to assess higher-level patterns delineating which species show this trait and which do not. 
Most simply, 6 of 8 species showed the anticipated negative slopes in the population trend-niche distance relationship. Our analyses, however, may have lacked the statistical power to detect a relationship that in reality exists in the remaining species. Of particular concern was the coarse spatial resolution of the BBS trend data $(25 \times 25 \mathrm{~km})$ compared with the niche distance data $(\sim 5 \times 5 \mathrm{~km})$, potentially obscuring relationships that may exist. Given that the BBS data represent one of the most detailed, long-term population datasets available for a major region and major taxon anywhere, further testing of our hypotheses may have to await data that are more detailed, perhaps via focus on single species, to obtain the needed spatial resolution.

Other concerns revolve around the niche models that we fitted to the data, especially in the case where species' occurrences were known to be peripheral within the environmental dimensions studied. Occurrence peripherality tends to lead to unwanted patterns of extrapolation in niche dimensions or truncation in parts of the suitable environment, such that niche estimates can be wildly erroneous (Owens et al. 2013). Consequently, although we took considerable precautions to control these effects (see 'Materials and methods'), if niche centroids were not calculated appropriately (e.g. presenting broad extrapolations), significant associations of niche centroid distances with population trend data might be masked.

Our revised interpretation - namely that niche distance effects may manifest only towards the extremes of the niche-saw more support. That is, the only significant relationships that we observed in comparisons of the outermost quartiles of niche centroid distances to the central quartiles showed negative tendencies in population trends. This result suggests that populations of species that are peripheral within ecological niche space tend to show negative relationships - i.e. population declines are concentrated at the most extreme distances; further, more detailed exploration of these ideas would require finer-resolution population trend data and could incorporate specific statistical tests for breakpoints or thresholds. The drivers of these relationships may relate to the population resilience and response to fragmentation of habitats under these extremes of habitable conditions (Holt et al. 2005). Clearly, these results beg further testing with improved data, but they are mostly in agreement with the results discussed previously by Curnutt et al. (1996) in the context of marginality in geographic space: these authors found that for 9 species of grassland spar- rows, the lowest rate of increase over a period of 20 years was at the sites with the lowest abundance, which is exactly what we hypothesized. However, Curnutt et al. (1996) analyzed their results from a spatiotemporal perspective, whereas we are explicitly moving from a spatial analysis to one in environmental (scenopoetic) niche space. Nevertheless, as long as there is a positive correlation between the conditions in geographic space and the conditions in environmental space (Lira-Noriega \& Manthey 2014), our results provide another possible explanation for the findings in Curnutt et al. (1996).

Our results were somewhat mixed, but we believe that these relationships are far from well understood, and should be tested in other taxa and study systems. The ideal test case would be a species that is limited geographically, at least in large part, by environmental tolerances rather than dispersal barriers (Saupe et al. 2012), and for which population trend data are available across the geographic distribution at roughly the same spatial resolution as the niche models that are calibrated. Correctly identifying causal factors impacting population fitness is vital to proper implementation of conservation measures, since continued survival of species requires populations with strong, positive growth trends (Primack 2006).

Minimally, our results suggest that conservation action at extreme sites within species' habitable conditions may be risky. That is, among this set of 8 threatened or endangered bird species in the United States, population trends tend towards the negative in populations that are peripheral within the set of habitable conditions for the species. Indeed, a recent study (Sánchez-Fernández et al. 2013) found that many protected areas are predicted to retain suitable environmental conditions for species under climate-change scenarios, but that conditions will often be close to the species' tolerance limits. This emerging result suggests that conservation efforts that protect populations at sites that are not central environmentally for the species may be effectively doomed to failure, and that the only way to maintain them would be by a strong set of source populations (Curnutt et al. 1996). In this sense, understanding the relationship between abundant centers in geographic and in niche space would be a priority for additional scrutiny of our hypothesis.

Acknowledgements. We thank Pete Hosner and Lynnette Dornak for their contributions to this project, as well as the broader University of Kansas Ecological Niche Modeling Group. 


\section{LITERATURE CITED}

Barve N, Barve V (2013) ENMGadgets: tools for pre and post processing in ENM workflows. https://github.com/ vijaybarve/ENMGadgets (accessed December 2013)

Barve N, Barve V, Jimenez-Valverde A, Lira-Noriega A and others (2011) The crucial role of the accessible area in ecological niche modeling and species distribution modeling. Ecol Modell 222:1810-1819

Brown JH (1984) On the relationship between abundance and distribution of species. Am Nat 124:255-279

Curnutt JL, Pimm SL, Maurer BA (1996) Population variability of sparrows in space and time. Oikos 76:131-144

Elith J, Phillips SJ, Hastie T, Dudik M, Chee YE, Yates CJ (2011) A statistical explanation of MaxEnt for ecologists. Divers Distrib 17:43-57

Furrer R, Nychka D, Sain S (2012) Fields: tools for spatial data, R Package Version 6.7.

Hengeveld R (1992) Dynamic biogeography. Cambridge University Press, Cambridge

Hijmans RJ, Cameron SE, Parra JL, Jones PG, Jarvis A (2005) Very high resolution interpolated climate surfaces for global land areas. Int J Climatol 25:1965-1978

Hijmans RJ, Williams E, Vennes C (2012) Geosphere: spherical trigonometry, Version 1.2-28. R package. http://cran. r-project.org/web/packages/geosphere/geosphere.pdf

Holt RD, Keitt TH, Lewis MA, Maurer BA, Taper ML (2005) Theoretical models of species' borders: single species approaches. Oikos 108:18-27

Lawton JH (1993) Range, population abundance and conservation. Trends Ecol Evol 8:409-413

Lesica P, Allendorf FW (1995) When are peripheral populations valuable for conservation. Conserv Biol 9:753-760

Link WAS Jr (1994) Estimating equations estimates of trends. Bird Populations 2:23-32

Lira-Noriega A, Manthey JD (2014) Relationship of genetic diversity and niche centrality: a survey and analysis. Evolution 68:1082-1093

Martínez-Meyer E, Diaz-Porras D, Peterson AT, YanezArenas C (2013) Ecological niche structure and rangewide abundance patterns of species. Biol Lett 9:20120637

Myers CE, Saupe EE (2013) A macroevolutionary expansion of the modern synthesis and the importance of extrinsic abiotic factors. Palaeontology 56:1179-1198

Owens HL, Campbell LP, Dornak LL, Saupe EE and others (2013) Constraints on interpretation of ecological niche models by limited environmental ranges on calibration areas. Ecol Modell 263:10-18

Editorial responsibility: Dave Roberts,

Canterbury, UK
Pearson RG, Raxworthy CJ, Nakamura M, Peterson AT (2007) Predicting species distributions from small numbers of occurrence records: a test case using cryptic geckos in Madagascar. J Biogeogr 34:102-117

> Peterson AT, Pape M, Soberón J (2008) Rethinking receiver operating characteristic analysis applications in ecological niche modeling. Ecol Modell 213:63-72

Peterson AT, Soberón J, Pearson RG, Anderson RP, Martínez-Meyer E, Nakamura M, Araújo MB (2011) Ecological niches and geographic distributions. Princeton University Press, Princeton, NJ

Phillips SJ, Anderson RP, Schapire RE (2006) Maximum entropy modeling of species geographic distributions. Ecol Modell 190:231-259

Primack RB (2006) Essentials of conservation biology, 4th edn. Sinauer Associates, Sunderland, MA

R Core Team (2013) R: a language and environment for statistical computing. R Foundation for Statistical Computing, Vienna

Sagarin RD, Gaines SD (2002) The 'abundant centre' distribution: To what extent is it a biogeographical rule? Ecol Lett 5:137-147

> Sánchez-Fernández D, Abellan P, Picazo F, Millan A, Ribera I, Lobo JM (2013) Do protected areas represent species' optimal climatic conditions? A test using Iberian water beetles. Divers Distrib 19:1407-1417

Sauer JR, Hines JE, Fallon JE, Pardieck KL, Ziolkowski DJ Jr, Link WA (2012) The North American breeding bird survey, results and analysis 1966-2011. USGS Patuxent Wildlife Research Center, Laurel, MD

Saupe EE, Barve V, Myers CE, Soberon J and others (2012) Variation in niche and distribution model performance: the need for a priori assessment of key causal factors. Ecol Modell 237/238:11-22

> Sibly RM, Barker D, Denham MC, Hone J, Pagel M (2005) On the regulation of populations of mammals, birds, fish, and insects. Science 309:607-610

Soberón J (2007) Grinnellian and Eltonian niches and geographic distributions of species. Ecol Lett 10:1115-1123

Sullivan BL, Aycrigg JL, Barry JH, Bonney RE and others (2014) The eBird enterprise: an integrated approach to development and application of citizen science. Biol Conserv 169:31-40

Yañez-Arenas C, Martínez-Meyer E, Mandujano S, RojasSoto O (2012) Modelling geographic patterns of population density of the white-tailed deer in central Mexico by implementing ecological niche theory. Oikos 121: 2081-2089

Submitted: March 31, 2014; Accepted: August 27, 2014 Proofs received from author(s): November 17, 2014 